J. Lake Sci. (湖泊科学), $2006, \mathbf{1 8}(4): 387-394$

http:// www. jlakes. org. E-mail: jlakes@ niglas. ac.cn

(c) 2006 by Journal of Lake Sciences

\title{
红壤小流域不同土地利用方式坡面下水塘底泥养分含量变化”
}

\author{
王晓龙 ${ }^{1,2}$, 胡 锋 ${ }^{1 * *}$, 李辉信 ${ }^{1}$, 秦江涛 ${ }^{1}$, 张 斌 ${ }^{3}$ \\ ( 1 : 南京农业大学 资源与环境学院, 南京 210095) \\ (2: 中国科学院生态环境研究中心系统生态重点实验室, 北京 100085) \\ (3: 中国科学院南京土壤研究所,南京 210008)
}

\begin{abstract}
摘 要: 以我国南方丘陵区红壤小流域为研究对象, 对不同土地利用方式坡面下的 4 个水塘底泥中养分含量作了分层比 较研究 $(0-5 \mathrm{~cm}, 5-10 \mathrm{~cm}, 10-15 \mathrm{~cm}, 15-20 \mathrm{~cm}, 20-25 \mathrm{~cm}, 25-30 \mathrm{~cm})$. 结果表明:4 个水塘底泥养分含量差异明显, 在 $0-15 \mathrm{~cm}$ 泥层有机碳、全氮、速效氮和全磷含量以邻近村庄的水塘( 简称 C 塘) 底泥最高, 其次为板栗园坡下的水塘( 简 称 $\mathrm{B}$ 塘), 水稻田坡面下水塘 (简称 $\mathrm{S}$ 塘) 和花生地坡面下水塘 (简称 $\mathrm{H}$ 塘) 最低; 在 $15-30 \mathrm{~cm}$ 泥层, 有机碳和速效氮含量 以 B 塘最高, 而全氮和全磷含量则以 $\mathrm{C}$ 塘最高; 有效磷含量除 $\mathrm{C}$ 塘 $0-15 \mathrm{~cm}$ 底泥外, 其余均为痕量. 表明土地利用方式对 其坡面下水塘底泥养分含量影响明显. 各水塘底泥养分随泥层加深均呈递减趋势, 其中全氮和速效氮减幅以 $\mathrm{C}$ 塘最大, 分 别为 $36.0 \%$ 和 $38.7 \%$, 有机碳和全磷减幅则以 B 塘最大, 为 $29.4 \%$ 和 $31.9 \%$; 各塘底泥养分含量的最大降幅主要在浅层 底泥, 水塘养分积累加速表明近年来农村面源污染加剧. 传统农业耕作方式的改变是农村水体底泥养分含量增加的主要 原因之一.
\end{abstract}

关键词:红壤小流域;土地利用方式;底泥;养分含量

\section{Variations of the nutrient concentrations in the sediments of ponds under the slopes of dif- ferent land use patterns in small red soil watershed}

WANG Xiaolong ${ }^{1,2}$, HU Feng ${ }^{1}$, LI Huixing ${ }^{1}$, QIN Jiangtao ${ }^{1} \&$ ZHANG Bin $^{3}$

(1:College of Resource and Environmental Sciences, Nanjing Agriculture University, Nanjing 210095)

(2: Key Laboratory of Systems Ecology Research Center for Eco-environmental Sciences, CAS, Beijing 100085 P. R. China )

(3:Institute of Soil Science, CAS, Nanjing 210008,P. R. China. )

Abstract: Based on the low hill small red soil watershed in the Ecological Experiment Station of Red Soil of China
Academy of Sciences, the variations of nutrient concentrations in the sediments $(0-5 \mathrm{~cm}, 5-10 \mathrm{~cm}, 10-15 \mathrm{~cm}$,
$15-20 \mathrm{~cm}, 20-25 \mathrm{~cm}, 25-30 \mathrm{~cm}$ ) of 4 ponds under the slopes of different land use patterns were investigated.
The 4 ponds were B pond ( locateal in the downside slope of Chinese chestnut land), C pond (locateal in the vicin-
ity of the village), H pond (locateal in the downside slope of peanut land) and $\mathrm{S}$ pond (locateal in the downside
slope of paddy field respectively. The results showed that: The nutrient concentrations in sediment of 4 ponds were
differed obviously. The highest concentrations of TOC, TN, AN and TP in $0-15 \mathrm{~cm}$ sediment were appeared in C
pond, and the lowest were in $\mathrm{H}$ pond. In $15-30 \mathrm{~cm}$ sediment, the highest concentrations of TOC and AN were
found in B pond, while TN and TP were found in C pond. The concentrations of AP of the sediment in 4 ponds
were trace except the $0-15 \mathrm{~cm}$ sediment in $\mathrm{C}$ pond with low level. This suggested that the land use patterns had
significant effect on the nutrient concentrations in the sediments of the ponds. The nutrient concentrations of the

* 国家自然科学基金项目 (49871046)、中国科学院红壤生态开放试验站基金项目共同资助. $2005-09-17$ 收稿; $2005-12-01$ 收修改稿. 王晓龙,男,1977 年生,博士生.

** 通讯作者:E-mail:fenghu@ niau.edu.cn 
sediments $(0-30 \mathrm{~cm})$ in 4 ponds all decreased from surface to bottom. The TN and AN with the maximal descent were found in C pond, and the TOC and TP were both in B pond. The most descents of nutrient concentrations in sediment in each pond appeared in superficial sediment layers. The accelerations of the nutrient accumulating in sediment indicated that the export of nutrient from each land use pattern had increased in recent years obviously, and one of the main causes of the nutrient enhancement in the sediment was the transform of the traditional agricultural cultivation fashions.

Keywords: Small red soil watershed; land used pattern; sediment; nutrient concentration

水体底泥作为水体 3 大环境要素 (水质、水生生物和底泥)之一, 是水体中营养物质的重要蓄积库,在 沉淀和释放污染物方面起着重要作用,有时也是形成水体富营养化的关键因素之一 ${ }^{[1,2]}$. 我国南方红壤丘 陵区由于不合理的种植制度和耕作方式, 每年水土流失不仅造成大量的 $\mathrm{N} 、 \mathrm{P}$ 等养分元素损失, 使土壤质量 退化, 土地生产力降低, 同时这些养分元素及侵蚀泥砂进人水体后也促使水体富营养化和水体底泥淤积, 严 重危害了当地的农村生态环境和人们生活质量 ${ }^{[3-6]} .80$ 年代以来,我国学者在湖泊底泥沉积的空间分布规 律和底泥 N、P 养分释放特征对水体富营养化的影响等方面做了大量研究和报道, 同时对影响底泥养分释 放 - 吸附动态平衡的环境因素也做了许多研究工作 ${ }^{[7-15]}$. 但这些工作主要集中在城市周边大型的湖泊和 水库, 以及对底泥养分动态平衡的机理研究, 对于农村小型水体的富营养化及底泥养分含量的调查研究则 很少涉及. 本研究以我国南方红壤小流域为研究对象, 对流域内不同土地利用方式下水体底泥的养分含量 进行分析研究, 旨在揭示该地区农业土地利用方式对农村小型水体底泥养分沉积特征的影响, 为控制该地 区小型水体淤积和富营养化,促进当地农村生态环境的改善提供科学依据.

\section{1 材料与方法}

\section{1 样地概况}

本研究在中国科学院红壤生态开放试验站孙家小流域进行, 该小流域位于江西省余江县,地处我国中 亚热带地区, 属亚热带季风区,气候温热多雨, 年均日照 $1809.5 \mathrm{~h}$, 年均气温 $17.6^{\circ} \mathrm{C}$, 多年平均降水量 1794.7 $\mathrm{mm}$, 年蒸发量为 $1318 \mathrm{~mm}$. 小流域面积为 $46.2 \mathrm{hm}^{2}$, 土壤类型为发育于白严系红砂岩和第四系红粘土的红 壤和水稻土. 地形地貌为地丘岗冲地, 海拔为 41.0-54.8m, 相对高差 $15-30 \mathrm{~m}$, 主要利用方式为林业、农林 复合利用、旱作农业和水稻,水体面积约 $0.6 \mathrm{hm}^{2}$. 小流域所有土地资源均已开发利用,但由于利用方式不合 理,加上该地区降雨集中,土壤扰动强烈, 水土流失严重 ${ }^{[16]}$.

本研究选择了该小流域不同土地利用方式下 4 个小型水体. 分别为: 板栗园西塘( B 塘)、水稻田西塘 ( $\mathrm{S}$ 塘)、花生地西边藕塘 ( $\mathrm{H}$ 塘)、村口塘 ( $\mathrm{C}$ 塘), 各水体自 80 年代末,除 $\mathrm{H}$ 塘南部每年采藕外, 基本没有清 塘等对底泥扰动较大的行为, 故各水体底泥淤积深厚, 其中 B 塘位于小流域板栗园西坡下部, 面积约 0.15 $\mathrm{hm}^{2}$, 池塘南部底泥层深厚, 北部则为硬质黏土. 进水口位于北部, 进水量少, 为半封闭水体, 高温夏季有水 华产生; 由于西北部为灌溉沟渠隔开, 降雨时只有板栗园坡面径流水及泥砂进人水体. $\mathrm{S}$ 塘位于小流域东南 部, 面积约 $0.2 \mathrm{hm}^{2}$, 底泥较厚, 且分布均匀. 池塘北部由灌溉沟渠与旱坡地隔开, 东面和南面的水稻田引自 北面灌溉渠的水不间断的排人水体, 由池塘西部的出水口排出, 水体更新快. 降雨时主要是水稻田径流水及 泥砂进人. $\mathrm{H}$ 塘位于花生地西侧, 面积约 $0.15 \mathrm{hm}^{2}$, 南部种藕, 北部生长芦苇. 底泥淤积深, 池塘北部进水口 有水不断排人,水体更新较快. 降雨时主要有东面花生地和花 - 橘间作地表径流进人. C 塘紧邻村庄西部, 面积约 $0.1 \mathrm{hm}^{2}$, 没有明显的进水口和出水口, 底泥淤积层厚, 水体常年有水华产生, 水体更新慢, 降雨时主 要有来自村庄径流进人水体.

\section{2 样品采集}

2002 年 7 月中旬用柱状泥样采集器对 $\mathrm{B}$ 塘、S 塘、H 塘和 C 塘分别进行随机多点采样, 每个样地采集 3 个混合样, 用于统计分析. 每个样本采集 6 层泥样 $(0-5 \mathrm{~cm}, 5-10 \mathrm{~cm}, 10-15 \mathrm{~cm}, 15-20 \mathrm{~cm}, 20-25 \mathrm{~cm}$ 和 $25-30 \mathrm{~cm}$ ). 样品密封运回实验室, 自然风干后, 过 20 目和 100 目土䇻. 其中 $\mathrm{H}$ 塘因南部藕区泥层扰动较 大,泥样主要在北部芦苇区采集. 同时多点混合采集了各水塘坡面上的花生地、花 - 橘间作、板栗园、水稻田 
4 种不同土地利用方式表层土壤 $(0-5 \mathrm{~cm})$, 用于测定表层土壤养分含量( 由于无法确定有代表性的样点, 本研究中没有采集村庄中的表层土壤).

表 1 不同利用方式下表层土壤养分含量 $(0-5 \mathrm{~cm})$

Tab. 1 Contents of nutrients in surface soil layer under different land use patterns $(0-5 \mathrm{~cm})$

\begin{tabular}{|c|c|c|c|c|c|c|c|}
\hline & $\mathrm{pH}$ & 有机碳 $(\mathrm{g} / \mathrm{kg})$ & 全 & 氮 $(\mathrm{g} / \mathrm{kg})$ & 有效氮 $(\mathrm{mg} / \mathrm{kg})$ 全 & 磷 $(\mathrm{g} / \mathrm{kg})$ & 有效磷 $(\mathrm{mg} / \mathrm{kg})$ \\
\hline 花生地 & 5.1 & 6.77 & & 0.70 & 75.23 & 0.45 & 45.76 \\
\hline 花 - 橘间作 & 5.1 & 7.09 & & 0.69 & 67.36 & 0.36 & 30.02 \\
\hline 板栗园 & 5.2 & 12.35 & & 0.81 & 94.42 & 0.34 & 26.10 \\
\hline 水稻田 & 6.5 & 19.8 & & 80.99 & 118.6 & 0.64 & 66.60 \\
\hline
\end{tabular}

\section{3 样品分析}

分析方法均为常规法: $\mathrm{pH}$, 酸度计测定 (土：水为 1：2.5) ; 有机碳, 重铬酸钾氧化法; 全氮, 凯氏法; 全 磷, 高氯酸消化、钼锑抗比色法; 速效氮 (碱解氮), 康维血扩散法; 速效磷, 双酸浸提、钼锑抗比色法 ${ }^{[17]}$.

\section{4 数据统计分析}

单因素方差分析 (One - Way ANOVA) 和双变量相关分析 (Pearson) 采用 SPSS 统计软件, 显著性水平设 置为 $P<0.05$, 其中用 $\mathrm{a} 、 \mathrm{~b} 、 \mathrm{c} 、 \mathrm{~d}$ 不同字母分别表示方差分析结果达到显著性差异的样地.

\section{2 结果与分析}

\section{1 不同利用方式下水体底泥 $\mathrm{pH}$ 分异}

由表 2 可见,4 个水塘底泥 $\mathrm{pH}$ 值变化范围不大,在 $7.32-7.59$ 之间. 在 $0-5 \mathrm{~cm}$ 和 $5-10 \mathrm{~cm}$ 泥层 $\mathrm{S}$ 塘 和 $\mathrm{H}$ 塘 $\mathrm{pH}$ 高于 $\mathrm{B}$ 塘和 $\mathrm{C}$ 塘, 差异达到显著水平. $10-15 \mathrm{~cm}$ 泥层 $\mathrm{pH}$ 值 $\mathrm{C}$ 塘显著低于其他各塘. 而在 $15-$ $20 \mathrm{~cm}, 20-25 \mathrm{~cm}$ 和 $25-30 \mathrm{~cm}$ 泥层四个 4 水塘底泥 $\mathrm{pH}$ 值则无显著差异. 总体上, 各塘底泥 $\mathrm{pH}$ 值随土层的 加深均呈增高趋势. 我国南方红壤地区由于强淋溶作用, 土壤普遍呈酸性特征, $\mathrm{pH}$ 值一般在 $4.3-6.5$ 之 间 ${ }^{[4]}$. 表层土壤由于侵蚀作用进人水体后, 在淹水条件下, 氧化电位降低, 土壤中的铝离子活性减低, 从而 使水塘底泥 $\mathrm{pH}$ 值上升 ${ }^{[16]}$.

表 2 不同利用方式下水体底泥 $\mathrm{pH}$ 分异

Tab. 2 Variance of $\mathrm{pH}$ in the sediments of ponds under different land use patterns

\begin{tabular}{ccccccc}
\hline \multirow{2}{*}{ 样 地 } & \multicolumn{7}{c}{ 底泥层次 $(\mathrm{cm})$} \\
\cline { 2 - 6 } & $0-5$ & $5-10$ & $10-15$ & $15-20$ & $20-25$ & $25-30$ \\
\hline B 塘 & $7.32 \mathrm{~b}^{1)}$ & $7.37 \mathrm{~b}$ & $7.50 \mathrm{a}$ & $7.51 \mathrm{a}$ & $7.54 \mathrm{a}$ & $7.59 \mathrm{a}$ \\
$\mathrm{S}$ 塘 & $7.46 \mathrm{a}$ & $7.47 \mathrm{a}$ & $7.46 \mathrm{a}$ & $7.49 \mathrm{a}$ & $7.50 \mathrm{a}$ & $7.51 \mathrm{a}$ \\
H 塘 & $7.46 \mathrm{a}$ & $7.47 \mathrm{a}$ & $7.47 \mathrm{a}$ & $7.48 \mathrm{a}$ & $7.49 \mathrm{a}$ & $7.51 \mathrm{a}$ \\
C 塘 & $7.33 \mathrm{~b}$ & $7.34 \mathrm{~b}$ & $7.34 \mathrm{~b}$ & $7.47 \mathrm{a}$ & $7.47 \mathrm{a}$ & $7.50 \mathrm{a}$ \\
\hline
\end{tabular}

1) 列中字母若不相同, 表明样地之间存在显著差异 $(P<0.05, n=3$, 邓肯法 $)$,下同.

\section{2 不同利用方式下水体底泥有机碳含量分异}

表 3 中, $0-5 \mathrm{~cm}, 5-10 \mathrm{~cm}, 10-15 \mathrm{~cm}$ 和 $15-20 \mathrm{~cm}$ 泥层有机碳含量各塘分异基本一致, C 塘 > B 塘 > $\mathrm{S}$ 塘 $>\mathrm{H}$ 塘, 其中 0 -5 cm 泥层各塘差异达到显著性水平, 5-10 cm, 10 - 15 cm 和 $15-20 \mathrm{~cm}$ 泥层 $\mathrm{C}$ 塘和 $\mathrm{B}$ 塘有机碳含量显著高于 $\mathrm{S}$ 塘和 $\mathrm{H}$ 塘. $20-25 \mathrm{~cm}$ 和 $25-30 \mathrm{~cm}$ 泥层有机碳含量依次为 $\mathrm{B}$ 塘 $>\mathrm{C}$ 塘 $>\mathrm{H}$ 塘 $>\mathrm{S}$ 塘, 其中 $\mathrm{B}$ 塘和 $\mathrm{C}$ 塘显著高于 $\mathrm{H}$ 塘和 $\mathrm{S}$ 塘. 底泥中的有机碳主要来自于侵蚀泥砂携带进入和水体生物死亡 沉积. 靠近村庄的水塘 ( $\mathrm{C}$ 塘) 由于村庄里的枯枝落叶和畜禽粪便在降雨时可进人水体, 同时夏季繁殖的水 藻死亡后在底泥中大量沉积, 因而底泥有机碳要高于其他水塘. $\mathrm{B}$ 塘底泥有机碳高于 $\mathrm{S}$ 塘和 $\mathrm{H}$ 塘, 可能主要 
是因为板栗园地表堆积的大量植被调落物进人水体沉积的原因. 而 $\mathrm{S}$ 塘底泥有机碳高于 $\mathrm{H}$ 塘, 则可能是因 为水稻田土壤有机碳高于花生地, 因而进入 $S$ 塘的侵蚀泥砂携带的有机碳也较高. 与 $0-20 \mathrm{~cm}$ 泥层相比, $20-30 \mathrm{~cm}$ 泥层各水塘有机碳含量差异缩小, 这可能与底泥有机碳稳定性有关. 从不同层次底泥有机碳含量 可以看出, 各塘底泥有机碳含量均以表层最高, 然后随泥层的加深而降低. 从 $0-5 \mathrm{~cm}$ 到 $25-30 \mathrm{~cm}$ 泥层, 各 塘有机碳含量减幅分别为 $\mathrm{B}$ 塘 $29.4 \% 、 \mathrm{~S}$ 塘 $32.9 \% 、 \mathrm{H}$ 塘 $13.7 \%$ 、 塘 $41.5 \%$, 以 $\mathrm{C}$ 塘和 $\mathrm{S}$ 塘最高, $\mathrm{H}$ 塘最 低; $\mathrm{C}$ 塘和 $\mathrm{B}$ 塘在 $0-5 \mathrm{~cm}$ 和 5-10 $\mathrm{cm}$ 泥层之间有个明显的降低过程, 可能是因为 $\mathrm{C}$ 塘和 $\mathrm{B}$ 塘表层底泥含 有大量植物残体, 活性较高, 易于分解.

表 3 不同利用方式下水体底泥有机碳含量分异 $(\mathrm{g} / \mathrm{kg})$

Tab. 3 Variance of the contents of TOC in the sediments of ponds under different land use patterns $(\mathrm{g} / \mathrm{kg})$

\begin{tabular}{ccccccc}
\hline \multirow{2}{*}{ 样 地 } & \multicolumn{7}{c}{ 底泥层次 $(\mathrm{cm})$} \\
\cline { 2 - 7 } & $0-5$ & $5-10$ & $10-15$ & $15-20$ & $20-25$ & $25-30$ \\
\hline B 塘 & $15.63 \mathrm{~b}$ & $13.07 \mathrm{a}$ & $12.96 \mathrm{a}$ & $12.68 \mathrm{a}$ & $11.75 \mathrm{a}$ & $11.05 \mathrm{a}$ \\
$\mathrm{S}$ 塘 & $13.78 \mathrm{c}$ & $12.59 \mathrm{~b}$ & $10.63 \mathrm{~b}$ & $10.46 \mathrm{~b}$ & $9.46 \mathrm{~b}$ & $9.25 \mathrm{~b}$ \\
H 塘 & $10.44 \mathrm{~d}$ & $10.24 \mathrm{c}$ & $9.88 \mathrm{~b}$ & $9.75 \mathrm{~b}$ & $9.38 \mathrm{~b}$ & $9.01 \mathrm{~b}$ \\
C 塘 & $18.25 \mathrm{a}$ & $14.53 \mathrm{a}$ & $13.42 \mathrm{a}$ & $13.10 \mathrm{a}$ & $11.72 \mathrm{a}$ & $10.68 \mathrm{a}$ \\
\hline
\end{tabular}

\section{3 不同利用方式下水体底泥全氮、速效氮含量分异}

表 4 中,在 $0-5 \mathrm{~cm}$ 和 5-10 cm 泥层全氮含量 $\mathrm{C}$ 塘 $>\mathrm{B}$ 塘 $>\mathrm{S}$ 塘 $>\mathrm{H}$ 塘, 且各塘之间差异均达到了显著 水平; 在 $10-15 \mathrm{~cm}, 15-20 \mathrm{~cm}, 20-25 \mathrm{~cm}$ 和 $25-30 \mathrm{~cm}$ 泥层各塘全氮含量分异趋势与 $0-5 \mathrm{~cm}$ 和 $5-10$ $\mathrm{cm}$ 泥层一致,但各塘之间均没有达到显著性差异.

表 5 中各塘底泥速效氮含量范围在 $81.63-356.24 \mathrm{mg} / \mathrm{kg}$ 之间. $0-5 \mathrm{~cm}, 5-10 \mathrm{~cm}$ 和 $10-15 \mathrm{~cm}$ 泥层 速效氮含量 $\mathrm{C}$ 塘 $>\mathrm{B}$ 塘 $>\mathrm{S}$ 塘 $>\mathrm{H}$ 塘, 与全氮含量分异一致, 其中 $\mathrm{C}$ 塘显著最高, $\mathrm{H}$ 塘则显著低于其他样 地, B 塘和 $\mathrm{S}$ 塘无显著性差异. $15-20 \mathrm{~cm}$ 泥层有效氮含量 $\mathrm{B}$ 塘 $>\mathrm{C}$ 塘 $>\mathrm{S}$ 塘 $>\mathrm{H}$ 塘, 其中 $\mathrm{B}$ 塘、C 塘和 $\mathrm{S}$ 塘 之间均无显著性差异. $20-25 \mathrm{~cm}$ 和 $25-30 \mathrm{~cm}$ 泥层 B 塘 $>\mathrm{S}$ 塘 $>\mathrm{C}$ 塘 $>\mathrm{H}$ 塘, 其中 $\mathrm{S}$ 塘与 $\mathrm{B}$ 塘差异不显 著, 而二者与 $\mathrm{C}$ 塘和 $\mathrm{H}$ 塘达到显著性差异. 各水塘 0-30 cm 泥层全氮和速效氮含量均随泥层的加深而降 低. 从养分的垂直分布规律看, 各塘全氮和速效氮含量均随泥层的加深而降低. 从 $0-5 \mathrm{~cm}$ 到 $25-30 \mathrm{~cm}$ 泥 层全氮含量减幅以 $\mathrm{C}$ 塘最高为 $36.0 \%$, 其次为 $\mathrm{S}$ 塘 $32.9 \% 、 \mathrm{~B}$ 塘 $29.3 \% 、 \mathrm{H}$ 塘 $13.7 \%$, 其中 $\mathrm{C}$ 塘和 $\mathrm{B}$ 塘全 氮含量从 $0-5 \mathrm{~cm}$ 到 5-10 cm 泥层降幅明显; 速效氮含量减幅以 $\mathrm{C}$ 塘最高为 $38.7 \%$, 其次是 $\mathrm{H}$ 塘 $28.5 \% 、 \mathrm{~S}$ 塘 $19.0 \%$ 、 $\mathrm{B}$ 塘 $17.8 \%$, 其中 C 塘在 5-10 cm 和 10-15 cm 泥层间有明显下降过程, 而 $\mathrm{H}$ 塘表层底泥速效 氮含量低于 5-10 $\mathrm{cm}$ 泥层, 而后从 5-10 $\mathrm{cm}$ 到 $10-15 \mathrm{~cm}$ 泥层显著下降. 总体而言, 泥层间较大的养分含 量变化主要发生在较浅泥层, 随着泥层的加深,泥层间养分含量差异在减小.

表 4 不同利用方式下水体底泥全氮含量分异 $(\mathrm{g} / \mathrm{kg})$

Tab. 4 Variance of the contents of TN in the sediments of ponds under different land use patterns $(\mathrm{g} / \mathrm{kg})$

\begin{tabular}{ccccccc}
\hline \multirow{2}{*}{ 样 地 } & \multicolumn{7}{c}{ 底泥层次 $(\mathrm{cm})$} \\
\cline { 2 - 7 } & $0-5$ & $5-10$ & $10-15$ & $15-20$ & $20-25$ & $25-30$ \\
\hline B 塘 & $15.63 \mathrm{~b}$ & $13.57 \mathrm{~b}$ & $12.96 \mathrm{a}$ & $12.68 \mathrm{a}$ & $11.71 \mathrm{a}$ & $11.05 \mathrm{a}$ \\
$\mathrm{S}$ 塘 & $13.78 \mathrm{c}$ & $12.59 \mathrm{~b}$ & $10.63 \mathrm{~b}$ & $10.46 \mathrm{~b}$ & $9.28 \mathrm{~b}$ & $9.25 \mathrm{~b}$ \\
$\mathrm{H}$ 塘 & $10.44 \mathrm{~d}$ & $10.24 \mathrm{c}$ & $9.88 \mathrm{~b}$ & $9.75 \mathrm{~b}$ & $9.18 \mathrm{~b}$ & $9.01 \mathrm{~b}$ \\
$\mathrm{C}$ 塘 & $18.25 \mathrm{a}$ & $14.53 \mathrm{a}$ & $13.42 \mathrm{a}$ & $13.10 \mathrm{a}$ & $11.72 \mathrm{a}$ & $11.68 \mathrm{a}$ \\
\hline
\end{tabular}


表 5 不同利用方式下水体底泥速效氮含量分异 $(\mathrm{mg} / \mathrm{kg})$

Tab. 5 Variance of the contents of $\mathrm{AN}$ in the sediments of ponds under different land use patterns $(\mathrm{mg} / \mathrm{kg})$

\begin{tabular}{ccccccc}
\hline \multirow{2}{*}{ 样 地 } & \multicolumn{5}{c}{ 底泥层次 $(\mathrm{cm})$} \\
\cline { 2 - 7 } & $0-5$ & $5-10$ & $10-15$ & $15-20$ & $20-25$ & $25-30$ \\
\hline B 塘 & $295.14 \mathrm{~b}$ & $281.61 \mathrm{~b}$ & $275.46 \mathrm{~b}$ & $272.07 \mathrm{a}$ & $264.76 \mathrm{a}$ & $242.63 \mathrm{a}$ \\
$\mathrm{S}$ 塘 & $279.42 \mathrm{~b}$ & $275.29 \mathrm{~b}$ & $271.46 \mathrm{~b}$ & $256.23 \mathrm{a}$ & $244.48 \mathrm{a}$ & $226.42 \mathrm{~b}$ \\
$\mathrm{H}$ 塘 & $114.17 \mathrm{c}$ & $120.08 \mathrm{c}$ & $100.08 \mathrm{c}$ & $95.96 \mathrm{~b}$ & $90.27 \mathrm{c}$ & $81.63 \mathrm{c}$ \\
$\mathrm{C}$ 塘 & $356.24 \mathrm{a}$ & $324.61 \mathrm{a}$ & $278.65 \mathrm{a}$ & $265.41 \mathrm{a}$ & $222.38 \mathrm{~b}$ & $218.67 \mathrm{~b}$ \\
\hline
\end{tabular}

\section{4 不同利用方式下水体底泥全磷、速效磷含量分异}

表 6 中,各塘底泥全磷含量在 $0.23-1.24 \mathrm{~g} / \mathrm{kg}$ 范围内, 分异较大. 其中 $0-5 \mathrm{~cm}$ 和 $5-10 \mathrm{~cm}$ 泥层全磷 含量分异一致, $\mathrm{C}$ 塘 $>\mathrm{S}$ 塘 $>\mathrm{B}$ 塘 $>\mathrm{H}$ 塘, 差异均达到显著水平; 在 $10-15 \mathrm{~cm}$ 泥层 $\mathrm{B}$ 塘和 $\mathrm{S}$ 塘全磷含量无 显著性差异; $15 \mathrm{~cm}$ 泥层以下, 即 $15-20 \mathrm{~cm}, 20-25 \mathrm{~cm}$ 和 $25-30 \mathrm{~cm}$ 泥层全磷含量分异相同, C 塘 > B 塘 > $\mathrm{S}$ 塘 $>\mathrm{H}$ 塘, 各塘之间均达到显著性差异. 总体来看, $\mathrm{C}$ 塘 $0-30 \mathrm{~cm}$ 全磷含量显著最高, $\mathrm{H}$ 塘 $0-30 \mathrm{~cm}$ 则显 著低于其他水体底泥. 各塘全磷含量垂直分布规律与有机碳、全氮和有效氮基本一致, 在 $0-30 \mathrm{~cm}$ 泥层随 泥层的加深而降低, 各塘减幅依次为 B 塘: $31.9 \% 、 \mathrm{~S}$ 塘: $61.7 \% 、 \mathrm{H}$ 塘: $39.5 \% 、 \mathrm{C}$ 塘: $51.6 \%$, 其中各塘全磷 减幅最大值均出现在 0-5 cm 和 5-10 $\mathrm{cm}$ 泥层之间. 总体而言, 泥层间较大的养分含量变化主要发生在较 浅泥层, 随着泥层的加深, 泥层间养分含量差异在减小.

而在表 7 中,在调查的 4 个水塘中,除 $\mathrm{C}$ 塘外, $\mathrm{B}$ 塘、 $\mathrm{S}$ 塘和 $\mathrm{H}$ 塘底泥速效态磷含量均没有测出. $\mathrm{C}$ 塘 15 $-30 \mathrm{~cm}$ 泥层速效磷为痕量, $0-15 \mathrm{~cm}$ 速效磷含量也极低.

表 6 不同利用方式下水体底泥全磷含量分异 $(\mathrm{g} / \mathrm{kg})$

Tab. 6 Variance of the contents of TP in the sediments of ponds under different land use patterns $(\mathrm{g} / \mathrm{kg})$

\begin{tabular}{ccccccc}
\hline \multirow{2}{*}{ 样 地 } & \multicolumn{7}{c}{ 底泥层次 $(\mathrm{cm})$} \\
\cline { 2 - 7 } & $0-5$ & $5-10$ & $10-15$ & $15-20$ & $20-25$ & $25-30$ \\
\hline B 塘 & $0.69 \mathrm{c}$ & $0.55 \mathrm{c}$ & $0.53 \mathrm{~b}$ & $0.53 \mathrm{~b}$ & $0.49 \mathrm{~b}$ & $0.47 \mathrm{~b}$ \\
$\mathrm{~S}$ 塘 & $0.81 \mathrm{~b}$ & $0.65 \mathrm{~b}$ & $0.51 \mathrm{~b}$ & $0.41 \mathrm{c}$ & $0.38 \mathrm{c}$ & $0.31 \mathrm{c}$ \\
H 塘 & $0.38 \mathrm{~d}$ & $0.33 \mathrm{~d}$ & $0.29 \mathrm{c}$ & $0.26 \mathrm{~d}$ & $0.25 \mathrm{~d}$ & $0.23 \mathrm{~d}$ \\
$\mathrm{C}$ 塘 & $1.24 \mathrm{a}$ & $0.87 \mathrm{a}$ & $0.81 \mathrm{a}$ & $0.75 \mathrm{a}$ & $0.73 \mathrm{a}$ & $0.60 \mathrm{a}$ \\
\hline
\end{tabular}

表 7 不同利用方式下水体底泥速效磷含量分异 $(\mathrm{mg} / \mathrm{kg})$

Tab. 7 Variance of the contents of AP in the sediments of ponds under different land use patterns $(\mathrm{mg} / \mathrm{kg})$

\begin{tabular}{ccccccc}
\hline \multirow{2}{*}{ 样 地 } & \multicolumn{7}{c}{ 底泥层次 $(\mathrm{cm})$} \\
\cline { 2 - 6 } & $0-5$ & $5-10$ & $10-15$ & $15-20$ & $20-25$ & $25-30$ \\
\hline $\mathrm{B}$ 塘 & 痕量 & 痕量 & 痕量 & 痕量 & 痕量 & 痕量 \\
$\mathrm{S}$ 塘 & 痕量 & 痕量 & 痕量 & 痕量 & 痕量 & 痕量 \\
H 塘 & 痕量 & 痕量 & 痕量 & 痕量 & 痕量 & 痕量 \\
C 塘 & 0.87 & 1.11 & 0.45 & 痕量 & 痕量 & 痕量 \\
\hline
\end{tabular}

\section{5 水体底泥不同养分指标之间相关关系}

表 8 中底泥 $\mathrm{pH}$ 与不同养分含量之间均呈显著负相关,除速效氮外,均达到极显著水平. 有机碳、全氮、 速效氮和全磷两两之间相关性均达到极显著水平, 表明底泥养分含量之间高度相关, 这与大多数报道一 致 ${ }^{[18-20]}$. 底泥 $\mathrm{pH}$ 与养分含量呈显著负相关关系, 可能是因为侵蚀泥砂进人水体沉积后, $\mathrm{pH}$ 逐渐升高, 而 养分却随泥层的加深却逐渐降低. 此外, 也有报道认为底泥 $\mathrm{pH}$ 升高会促使致养分释放速率加快 ${ }^{[21,22]}$. 
表 8 水体底泥不同养分指标之间相关系数

Tab. 8 Correlation coefficients among the nutrient indices in sediments of ponds

\begin{tabular}{|c|c|c|c|c|c|}
\hline & $\mathrm{pH}$ & 有机碳 & 全氮 & 有效氮 & 全磷 \\
\hline $\mathrm{pH}$ & 1.000 & $-0.710^{* *}$ & $-0.517^{* *}$ & $-0.410^{*}$ & $-0.638^{* *}$ \\
\hline 有机碳 & & 1.000 & $0.830^{* *}$ & $0.751^{* *}$ & $0.903^{* *}$ \\
\hline 全氮 & & & 1.000 & $0.955^{* *}$ & $0.869^{* *}$ \\
\hline 有效氮 & & & & 1.000 & $0.792^{* *}$ \\
\hline 全磷 & & & & & $1.000^{*}$ \\
\hline
\end{tabular}

** 极显著水平 $P<0.01 ; *$ 显著水平 $P<0.05, n=72$

\section{3 讨论与结论}

湖泊表层底泥是水土界面物质 (物理的、化学的、生物的) 的积极交替带,也是湖泊营养物质循环的中 心环节, 底泥养分剖面垂直分布, 是不同时期沉积物情况的反映 ${ }^{[23]}$. 本研究中各塘底泥氮、磷养分含量从表 层到底层呈递减趋势, 表明长期以来, 该地区小型水体内氮、磷养分积累和输人的增大. 众多研究表明, 上世 纪 80 年代以来, 由于工农业的迅速发展, 导致我国大量湖泊富营养化, 同时, 水体养分的积累和增加, 也反 映在底泥中 $\mathrm{N} 、 \mathrm{P}$ 养分含量从底层到表层逐步提高 ${ }^{[24-26]}$.

$\mathrm{C}$ 塘全氮含量在 0-5 cm 到 5-10 cm 泥层间以及速效氮含量从 5-10 cm 和 $10-15 \mathrm{~cm}$ 泥层间有明显 的下降过程,显示近年来农村日常生活对水体中氮的贡献在增大, 而全氮和速效氮的最大降幅出现在不同 泥层, 可能是与底泥中不同含氮化合物分解程度不一致有关. B 塘全氮含量在 $0-5 \mathrm{~cm}$ 到 $5-10 \mathrm{~cm}$ 泥层间 降幅也很明显, 表明板栗园近年氮的输出量提高, 这可能是由于近年来板栗园经济效益好, 为提高板栗产量 而增加施肥量的结果. $\mathrm{H}$ 塘表层底泥速效氮含量低于 5-10 cm 泥层, 而后从 5-10 cm 到 $10-15 \mathrm{~cm}$ 泥层显 著下降,这也反映了农业利用方式对底泥养分含量的影响. $\mathrm{H}$ 塘坡面主要为花生地和花 - 橘间作, 速效氮含 量从 5-10 cm 到 10-15 cm 泥层显著下降可能是前几年由于花生价格较高,花生地农业投入较大的结果; 随着近几年花生价格的下降,一些花生地改为花 - 橘间作, 施肥量相应减少, 而表层底泥中速效氮易于溶 出, 从而导致 $\mathrm{H}$ 塘表层底泥速效氮含量较低. 各塘底泥中全磷含量均随泥层的加深而降低, 并且减幅最大 值均出现在 $0-5 \mathrm{~cm}$ 和 5-10 $\mathrm{cm}$ 泥层之间,这表明近年来小流域内水体中磷的积累率加速, 从而意味着该 地区水体环境有加剧恶化的趋势.

底泥养分含量主要取决于外源养分的沉积和底泥内源养分的吸附一释放过程. 此外,底泥养分形态和 水体更新速率对底泥养分含量也有一定影响 ${ }^{[24,27,28]}$. 一般认为, 水体底泥中的养分含量来源主要有两个途 径, 一是侵蚀泥砂进人水体时本身携带的养分; 二是水体藻类死亡体沉积而形成 ${ }^{[29]}$. 本研究中不同土地利 用坡面下的四个水塘中, C 塘中各泥层有机碳、全氮、有效氮和全磷含量显著最高, 其次为 B 塘和 $\mathrm{S}$ 塘, $\mathrm{H}$ 塘 有机碳、全氮、有效氮和全磷含量则远低于其他水体底泥, 可能有以下原因造成: 首先, 由于各水体坡面土地 利用方式不同, 易于侵蚀的表层土壤各种养分含量不一致, 造成进人水体沉积的侵蚀泥砂中养分含量差异 较大,因而促使各塘底泥的养分含量的分异. 花生地坡面下的 $\mathrm{H}$ 塘虽然泥砂侵蚀量大,但由于表层土壤养 分含量较低, 并且土壤中养分以施人的化学肥料为主, 极易溶于水而流失, 因而沉积泥砂中养分含量较低, 从而其底泥中养分含量明显低于其他水塘; $\mathrm{B}$ 塘和 $\mathrm{S}$ 塘坡面上的板栗园和水稻田表层土壤养分含量高, 并 且由于地表有植被或水层覆盖, 径流泥砂中养分富集率较高, 从而底泥养分高于 H 塘. C 塘底泥主要来自于 村庄中侵蚀泥砂沉积, 在降雨时村庄中放养的畜禽粪便会随侵蚀径流进人水塘沉积, 此外平时生活用水如 含磷洗涤液等的排人, 也会增加底泥养分含量; 其次, 水塘底泥养分除沉积泥砂携入外, 水表浮游动植物死 亡体沉积也是重要来源之一. B 塘和 C 塘是封闭水体, 夏季高温时产生水华, 富营养化特征明显, 而大量水 藻死亡沉积后, 会明显增加底泥养分含量. 最后, 底泥养分含量也受其内源养分释放与吸附速率有关. 已有 研究表明过水性水体营养化程度及底泥养分含量比死水性水体低 ${ }^{[14]} . \mathrm{S}$ 塘和 $\mathrm{H}$ 塘为过水性水塘, 底泥养分 释放后很快被移出, 从而加速了底泥养分的释放速度.

相比较而言, 底泥全氮、有效氮、全磷含量远较水体坡面土壤为高 (表 1 ), 这与已有对太湖底泥和湖区 
土壤研究结果报道不一致 ${ }^{[12]}$. 这是由于侵蚀泥沙中养分富集, 进人水体沉积的侵蚀泥砂携带养分较高; 其 次, 藻类死亡体会增加底泥养分含量. 本研究中各塘底泥中速效磷含量极低. 土壤中的磷进人水体后, 可能 发生一系列化学变化, 一部分磷很快被释放进人水体, 另一部分则被铁、铝等离子进一步固定, 以至有效磷 含量降低. Hedgs 等人的研究也表明了相似的结论 ${ }^{[30]}$. 本研究中 4 个水体中只有 $\mathrm{B}$ 塘和 $\mathrm{C}$ 塘在盛夏时产生 水华, 由于底泥速效磷含量较低, 水体中的磷主要来自外源输人. 夏季是该地区农忙季节, 施肥量大, 同时 降雨集中, 养分随径流输出可占全年流失量的 $60 \%-80 \%{ }^{[31]}$. 由于夏季农忙时人口增加和板栗园施加追 肥, C 塘和 $\mathrm{B}$ 塘在夏季有大量氮、磷等养分输人, 同时由于水体更新慢, 养分在水塘中的滞留期长, 从而诱 发了水华的产生; $\mathrm{H}$ 塘和 $\mathrm{S}$ 塘在夏季也有大量养分随径流输人, 但由于水体更新快, 养分在水塘中滞留期 短,因而水华不易产生.

相对国内大多数湖泊, 红壤小流域不同利用方式下各塘底泥养分含量平均较低. 靠近居民点的水塘和 板栗林坡面下的水塘底泥中养分含量要高于花生地和水稻田坡面下的水塘, 说明生活污水和果园径流养分 输人的水体底泥养分含量要高于农田径流养分输人的水体底泥. 从养分含量的垂直分布来看, 不同利用方 式下各塘底泥表层养分含量明显高于深层底泥, 表明近年来农村面源污染加剧. 其主要原因是农业耕作方 式的改变以及施肥量的增加, 特别是近年来, 由于农民壮年劳力大都外出打工, 传统的农业耕作方式如蓄积 和施用有机肥、清塘取肥等由于劳动力耗费较大已经逐渐被舍弃, 代之以大量施用化学肥料等对环境影响 较大的农作方式. 这些是造成农村生态环境恶化的主要原因之一. 此外, 市场经济行为通过对农村种植和施 肥方式的影响, 从而对农村环境造成的正面或负面的影响也不容忽视. 因此,继续保持可持续的传统农业耕 作方式, 合理种植经济作物, 加强对农村生活污水的处理, 对于保护我国农村生态环境有着重要意义.

\section{4 参考文献}

[1] 金相灿, 屠清瑛主编. 湖泊富营养化调查规范(第二版). 北京: 中国环境科学出版社, 1990.

[2] 范成新, 杨龙元, 张 路. 太湖底泥及其间隙水中氮磷垂直分布及其相互关系分析. 湖泊科学, 2000, 12 (4) :359-366.

[3] 李辉信, 胡 锋, 徐盛荣. 红壤丘陵区不同利用管理方式对土壤肥力的影响. 土壤通报, 1996,27(3): $114-116$.

４4］孙 波等. 我国中亚热带缓丘区红黏土壤肥力的演化.土壤学报, 1994,36(2):203-217.

[5] 王效举,龚子同. 红壤丘陵小区域不同利用方式下土壤的变化和预测. 土壤学报, 1998, 35(1):135 -139 .

[6] 梁 音, 张桃林, 史德明. 南方红壤丘陵区土壤侵蚀评价. 《红壤生态系统研究》(第三集). 北京: 中国 农业科技出版社. 1995.

[7] 杨汉东, 蔡述明. 武汉东湖的现代沉积速率及其与扰动的关系. 环境科学与技术, 1993,63 (4): 11 -13 .

[8] 严国安,谭智群,任 南. 武汉东湖水环境污染状况及控制和恢复对策. 环境科学与技术, 1994,67 (4) $: 19-23$.

[9] 马立珊,汪祖强, 张水铭等. 苏南太湖水系农业面源污染及其控制对策研究. 环境科学学报, 1997,17 (1) $: 39-47$.

[10］隋桂荣. 太湖表层沉积物中 OM、TN、TP 的现状与评价. 湖泊科学, 1996,8(4):319-324.

[11] 隋少峰,罗启芳. 武汉东湖底泥磷释放特点. 环境科学,2001,22(1):102-105.

[12] 袁旭音,陈 骏,陶于祥, 季峻峰, 许乃政. 太湖北部底泥中氮、磷的空间变化和环境意义. 地球化学, $2002, \mathbf{3 1}(4): 321-328$.

[13] Kim Lee-Hyung, Choi Euiso, Michael K Stenstrom. Sediment characteristics, phosphorus types and phosphorus release rates between river and lake sediments. Chemosphere, 2003, 50: $53-61$.

[14] 秦伯强, 胡维平, 高 光等. 太湖沉积物悬浮的动力机制及内源释放的概念性模式. 科学通报, 2003, 48(17) : $182-183$. 
[15] 李一平, 逢 勇, 向 军. 太湖水质时空分布特征及内源释放规律研究. 环境科学学报, 2005, 25(3): $300-306$.

[16] 赵其国等. 中国东部红壤地区土壤退化的时空变化、机理及调控. 北京:科学出版社,2002.

[17] 鲁如坤. 土壤农业化学分析. 北京:科学出版社,2000.

[18] 李震宇, 朱荫媚, 王 进. 杭州西湖沉积物的若干物理和化学性状. 湖泊科学, 1998,10(1):79-841.

[19] Liikanen ANU. Effects of temperature and oxygen availability on greenhouse gas and nutrient dynamics in sediment of a eutrophic mid-boreal lake. Biogeochemistry, 2002, 59:269-286.

[20] 张水元, 刘䀧霞, 华 俐. 太平湖水库水质的理化性质. 水生生物学报, 2000, 24(5):530-536.

[21] 金相灿,王圣瑞, 庞 燕. 太湖沉积物磷形态及 $\mathrm{pH}$ 值对磷释放的影响. 中国环境科学, 2004,24 (6): $707-711$.

[22] 付春平, 钟成华,邓春光. $\mathrm{pH}$ 与三峡库区底泥氮磷释放关系的试验. 重庆大学学报, 2004,27(10):125 $-127$.

[23] 李文朝. 东太湖沉积物中氮的积累与水生植物沉积. 中国环境科学, 1997,17(5):418-421.

[24] 范成新,秦伯强等. 梅梁湖和五里湖水一沉积物界面的物质交换. 湖泊科学, 1998,10(1):73-78.

[25] 李文朝, 陈开宁, 吴庆龙. 东太湖表层沉积物的磷的饱和度初步研究. 湖泊科学, 1998,10(3):49-54.

[26] 谢丽强,谢 平, 唐汇娟. 武汉东湖不同湖区底泥总磷含量及变化的研究. 水生生物学报, 2001, 25 (4) :305-310.

[27] Torrent J, Schwertmann U \& Barron V. Phosphate sorption by natural hematites. European J Soil Sci,1994, $45: 45-51$.

[28] Fabre A C. Inorganic phosphate in exposed sediments of the River Garonne. Hydrobiologica, 1992, 228:37 42.

[29] 李一平,逢 勇,丁 玲. 太湖富营养化控制机理模拟. 环境科学与技术, 2004,27(3):1-4.

[30] Hedges J, Stem J H. Carbon and nitrogen determination of carbonate containing solids . Limnol Oceanogr, $1984,29: 657-663$.

[31] 马 琨,王兆塞, 陈 欣等. 不同雨强条件下红壤坡地养分流失特征研究. 水土保持学报, 2002,16 (3) : $16-19$. 